\title{
A Spread Spectrum Clock Generator for DisplayPort 1.2 with a Hershey-Kiss Modulation Profile
}

\author{
Seung-Wook Oh ${ }^{*}$, Hyung-Min Park ${ }^{* *}$, Yong-Hwan Moon*, and Jin-Ku Kang*
}

\begin{abstract}
This paper describes a spread spectrum clock generator (SSCG) circuit for DisplayPort 1.2 standard. A Hershey-Kiss modulation profile is generated by dual sigma-delta modulators. The structure generates various modulation slopes to shape a non-linear modulation profile. The proposed SSCG for DisplayPort 1.2 generates clock signals with 5000 ppm down spreading with a Hershey-Kiss modulation profile at three different clock frequencies, $540 \mathrm{MHz}, 270 \mathrm{MHz}$ and $162 \mathrm{MHz}$. The measured peak power reduction is about $15.6 \mathrm{~dB}$ at $540 \mathrm{MHz}$ with the chip fabricated using a $0.13 \mu \mathrm{m}$ CMOS technology.
\end{abstract}

Index Terms-SSCG, PLL, Hershey-Kiss modulation profile, sigma-delta modulator, DisplayPort

\section{INTRODUCTION}

As the operation frequency of electronic devices increases, the electromagnetic interference (EMI) is generated and radiated to other devices. The spread spectrum clock generator (SSCG) is a PLL-based clock generator with an output frequency modulation to reduce the EMI. Amount of EMI reduction frequency varies on modulation profiles [1]. The linear modulation known as the triangular profile is commonly used because of its simplicity for implementation. With the triangular modulation profile, however, most of the harmonic energy is concentrated at the edges of the spectrum

Manuscript received Dec. 26, 2012; accepted Apr. 25, 2013

${ }^{*}$ Inha University - Electronics, Incheon, Korea

${ }^{* *}$ Hyundai-Autron, Seongnam, Gyeonggi-do, Korea

E-mail : jkang@inha.ac.kr distribution. On the other hand, the Hershey-Kiss profile shows a non-linear modulation profile, but generates a more uniformed spectral spreading. Therefore a better EMI peak reduction could be achieved with HersheyKiss modulation profile [2]. Conventionally the HersheyKiss profile modulator is implemented by read-onlymemory (ROM) [3]. In prior works the Hersey-Kiss profile or Hersey-Kiss-like profile was generated by look-up-table (LUT) [2], SRAM [3], piecewise linear modulation [4], and a Newton-Raphson method design [5]. Other various approaches are also reported [6-10].

This paper designed a SSCG for DisplayPort 1.2 with a non-linear Hershey-Kiss modulation profile. The modulation profile is generated using the dual sigmadelta modulators (SDM) [11]. Since the proposed modulators are based on the simple digital blocks, it can be modified to different applications and specifications. The DisplayPort 1.2 standard is a serial interface standard for display devices set by VESA. DisplayPort 1.2 serial interface should support three different data rates, which are $1.62 \mathrm{~Gb} / \mathrm{s}, 2.7 \mathrm{~Gb} / \mathrm{s}$, and $5.4 \mathrm{~Gb} / \mathrm{s}$. Therefore the spread spectrum clock generator should support $162 \mathrm{MHz}, 270 \mathrm{MHz}$, and $540 \mathrm{MHz}$ clock modes for 10:1 multiplexing to a serial line. Also, the modulation frequency is defined as from 30 to $33 \mathrm{KHz}$ with $0.5 \%$ down-spread frequency modulation [12].

The overview of the paper is as follows. Section II describes the main idea of the scheme and explains the design architecture of the proposed SSCG. Section III presents the circuit components in the SSCG. The measurement results are presented in Section IV and Section V concludes. 


\section{OPERATION AND ARCHITECTURE}

\section{Operation Principle}

The Hershey-Kiss modulation profile generates a more uniform spectral spreading in SSCG application compared to a triangular profile. Fig. 1 shows a HerseyKiss modulation profile. The slope of the Hersey-Kiss modulation profile gradually changes from minimum to maximum value. Therefore, it is key point to make the gradual slope variation in order to generate Hershey-Kiss modulation profile. The underlying principle of this paper is to build a Hershey-Kiss modulation profile for DisplayPort 1.2 standard using the dual sigma-delta modulators. Fig. 2 shows a block diagram of the proposed SSCG circuit for DisplayPort 1.2. The modulators of proposed circuit for the Hersey-Kiss modulation profile consist of a slope modulator (SM) and a division modulator (DM). The slope of the Hershey-

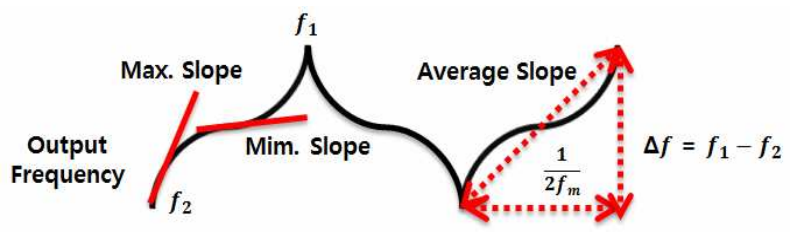

Fig. 1. Hershey-Kiss modulation profile with a slope change.

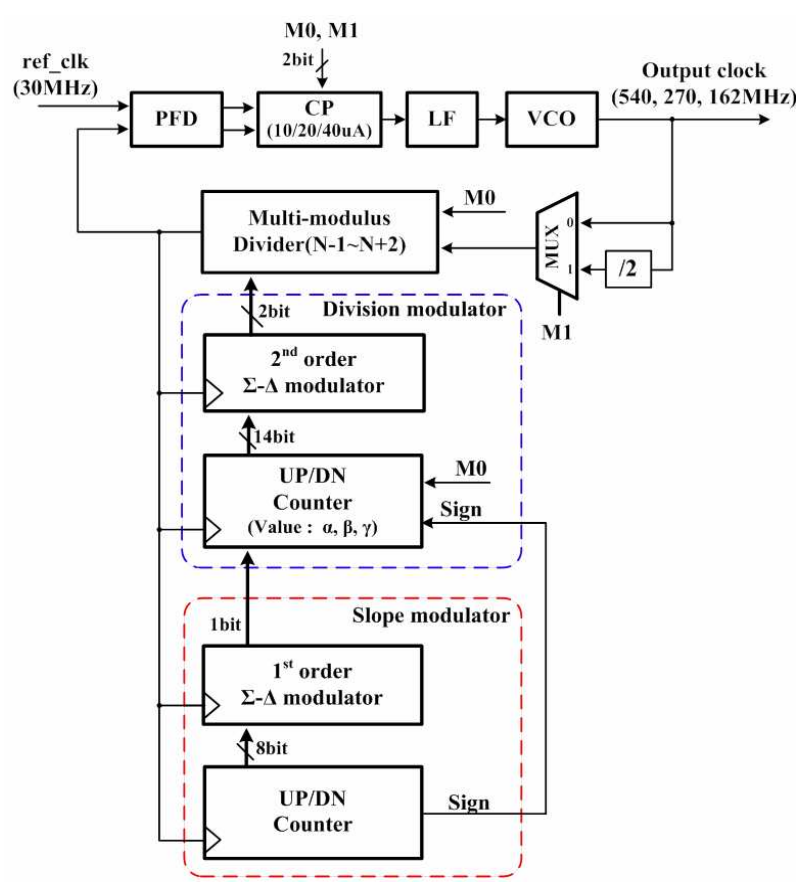

Fig. 2. The block diagram of the proposed SSCG.

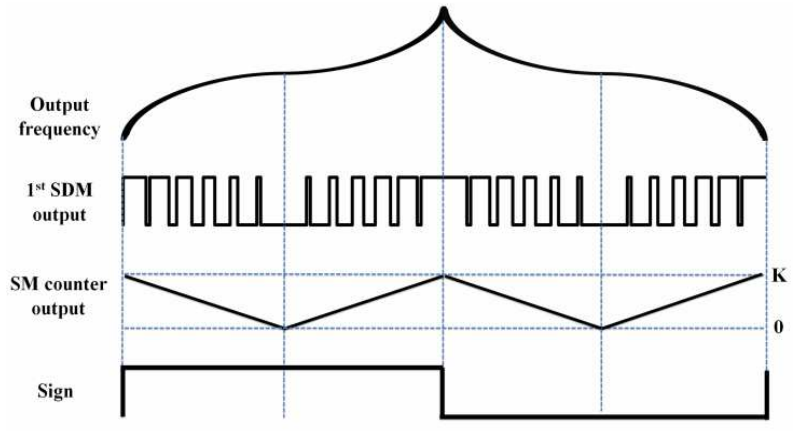

Fig. 3. The process of building the Hershey-Kiss modulation profile.

Kiss modulation profile repeats from the minimum and the maximum value, the derivative of its slope can be approximated to a triangular curve of SM counter output repeating itself with a twice of a modulation frequency. Fig. 3 shows the process of building the Hershey-Kiss modulation profile. The modulation profile has a very steep (maximum) slope at the ' $\mathrm{K}$ ' value of SM counter output and a slow (minimum) slope at the ' 0 ' value of SM counter output. The ' $\mathrm{K}$ ' is the largest number of the slope counter output will give the steepest slope. Though the Hershey-Kiss modulation profile is non-linear, the variation of its slope can be approximated and it has a periodicity as shown in Fig. 3. Therefore the HersheyKiss modulation profile can be generated by modulating its slope variation. The SM block provides gradual slope variation and sign (positive or negative) of profile slope to division modulator. The DM block provides a sigmadelta modulated division value for the PLL to multimodulus divider (MMD). Therefore the final output of the dual sigma-delta modulators will give an approximated Hershey-Kiss profile as shown in the top of Fig. 3. Therefore the PLL has a Hershey-Kiss modulation profile on the VCO control voltage and the output clock of VCO is spectrum-spread.

\section{ArChiteCture ANd OPERATION}

The proposed circuit has a fractional-N type PLL with a sigma-delta modulation. The circuit generates 540 $\mathrm{MHz}, 270 \mathrm{MHz}$, and $162 \mathrm{MHz}$ clocks for DisplayPort 1.2 serial interface with a reference clock of $30 \mathrm{MHz}$. Each link symbol clock is controlled by external switch signals which are M1, M0. The M1 changes the PLL loop path. When the M1 and M0 are set at both ' 0 ', the 
circuit operates in $162 \mathrm{MHz}$ and when M0 is set at ' 1 ', it operates $270 \mathrm{MHz}$ clock mode. When the M1 and M0 are set at both ' 1 ', the circuit operates in $540 \mathrm{MHz}$ clock mode. At the $540 \mathrm{MHz}$ clock mode, the output clock is divided by 2 before going into the loop. Each link symbol clock has different charge pump currents for its optimal loop bandwidth.

The SM block has a $1^{\text {st }}$ order SDM and an 8-bit up/down counter. The SM block generates a 1-bit output (SM output) and a 'Sign' output. The 8-bit counter output represents the profile slope and the 'Sign' output indicates the sign of the profile slope (positive or negative). Since the 8-bit up/down counter (SM counter) is used, the slope variation resolution is the $1 / 2^{8}$. When the SSCG operates, the SM counter repetitively sweeps the output from ' $\mathrm{K}$ ' to 0 . Whenever the output value reaches at ' $\mathrm{K}$ ', the 'Sign' signal switches its value from 0 to 1 and vice versa. The SM counter output shows a triangular profile as shown in Fig. 3. The SM block converts the counter value to a single bit randomized value. If the SM counter value goes up, the more 1's and the less 0 's can be seen at the SM output. If the slope counter value goes down, the more 0's and the less 1's can be seen at the SM output. Therefore the average value of the SM output is equivalent to the SM counter output value or the absolute value of the profile slope. So, the average value of the SM output (AVS) can be expressed by Eq. (1) [11].

$$
\mathrm{AVS}=\frac{\text { Output value of SM counter }}{2^{8}}
$$

The half period of the triangular slope curve is a quarter of the modulation period as shown in Fig. 3. Therefore the modulation frequency $\left(f_{m}\right)$ can be expressed by the reference clock frequency and the ' $\mathrm{K}$ ' value as given in Eq. (2) [11].

$$
f_{m}=\frac{\text { REF_CLK frequency }}{4}
$$

The DM block consists of a $2^{\text {nd }}$ order sigma-delta modulator and a 14-bit up/down counter (DM counter). The DM block provides the division value for the PLL. The increment or the decrement of the DM counter output value is decided by the 'Sign' signal from the SM counter. And the counter step size is determined by 'M0' switch, which is related to the operating frequency range. When the 'Sign' output is ' 1 ', the DM counter goes up. And when the 'Sign' output is ' 0 ', the DM counter counts down. If the SM counter value goes to a upper value, the more number of ' 1 ' outputs from the SM are provided as the DM counter, which will have the large counting step size and translate to the more and more steep slope. If the SM counter value goes to a lower value, the more number of ' 0 ' outputs from the SM, which will have small counting step size and translate to the more and more gentle slope. When the output from the SM is ' 0 ', the output value of the DM counter is increased or decreased by $\alpha$ or $\beta$ depending on the target output frequency. When the output value from the SM is ' 1 ', the output of the DM counter is increased or decreased by $\gamma$. Since the counting step size are set as $\gamma>$ $\beta>\alpha$.

In our previous work [11], the counting step value of $\alpha$ and $\beta$ is set 1 and 3 for proving the idea. In this work, we use three different counting steps as $\alpha, \beta$ and $\gamma$ and their values are set to 0,1 and 2 , respectively. The reason using the three parameters in this paper is to meet the three target frequencies (540 MHz, $270 \mathrm{MHz}, 162 \mathrm{MHz}$ ) for DisplayPort 1.2. Also, in order to make the smoother slope of Hershey-Kiss modulation profile and enhance the peak power reduction, the values of three counting step parameters are smaller than parameters in ref. [11].

When the M0 is set as ' 0 ', the DM is set for $162 \mathrm{MHz}$ operation and the step size of the DM counter is derived from $\alpha$ and $\gamma$. As a result, the slope variation is related to the AVS, $\alpha$ and $\gamma$ value when $\mathrm{M} 0=0$. The slope of the Hershey-Kiss profile can be expressed as

$$
\text { Slope of profile }=(\gamma-\alpha) \times A V S+\alpha \quad(\mathrm{M} 0=0)
$$

When the M0 is set as ' 1 ', the DM is set for $270 \mathrm{MHz}$ or $540 \mathrm{MHz}$ operation and the DM counter step values switch to $\beta$ and $\gamma$. Thus the slope is given as

$$
\text { Slope of profile }=(\gamma-\beta) \times A V S+\beta \quad(\mathrm{M} 0=1)
$$

The average slope can be express as follows:

$$
\text { Average slope }=\frac{D_{\max }-D_{\min }}{2 \times K}=\frac{\alpha+S_{\max }}{2}
$$


where $\mathrm{K}$ is the maximum value of the SM counter, and $D_{\text {max }}$ and $D_{\text {min }}$ are the maximum and minimum value of the DM counter output, respectively. And $S_{\max }$ is the maximum slope value and is given in Eq. (6) at each M0 value.

$$
\begin{aligned}
\mathrm{S}_{\max } & =(\gamma-\alpha) \times \operatorname{AVS}_{\text {max }}+\alpha \\
& =(\gamma-\alpha) \times \frac{\mathrm{K}}{2^{8}}+\alpha \quad(\mathrm{M} 0=0) \\
\mathrm{S}_{\max } & =(\gamma-\beta) \times \mathrm{AVS}_{\max }+\beta \\
& =(\gamma-\beta) \times \frac{\mathrm{K}}{2^{8}}+\beta \quad(\mathrm{M} 0=1)
\end{aligned}
$$

The spread ratio $(\delta)$ can be expressed using the DM counter values as follows: [11]

$$
\text { Spread ratio }(\delta)=\frac{\mathrm{D}_{\max }-\mathrm{D}_{\min }}{\mathrm{N} \times 2^{14}+\mathrm{D}_{\max }}
$$

Thus the spread ratio is controlled by the MMD and the DM counter. The values of $\mathrm{N}, \mathrm{D}_{\max }$, and $\mathrm{D}_{\min }$ can be determined by design parameters such as the reference clock, the targeted output frequency, and the spread ratio. Once the $\mathrm{D}_{\max }$ and $\mathrm{D}_{\min }$ are decided, the maximum value (K) of the SM counter can be derived from (3) to (5). For SSCG design of the three target frequencies, the maximum value of the SM counter is set as $248_{(10)}$. The values of $\mathrm{N}, \mathrm{D}_{\max }$ and $\mathrm{D}_{\min }$ at $162 \mathrm{MHz}$ mode are set as 5, $6554_{(10)}$ and $6111_{(10)}$, respectively, with a spread ratio of $5000 \mathrm{ppm}$ with $30 \mathrm{MHz}$ reference clock as defined in the DisplayPort 1.2 standard. When the modulator is set to $270 \mathrm{MHz}$ clock mode, the DM counter operates based on $\beta$ and $\gamma$ values. And the values of $N, D_{\max }$ and $D_{\min }$ are set as $8,16383_{(10)}$ and $15646_{(10)}$, respectively, at the 270 $\mathrm{MHz}$. At the $540 \mathrm{MHz}$ clock mode, $\mathrm{N}, \mathrm{D}_{\max }$ and $\mathrm{D}_{\text {min }}$ are set as same with $270 \mathrm{MHz}$ clock mode except that 540 $\mathrm{MHz}$ output clock is divided by 2 before going into the loop.

\section{CiRCuit COMPONENTS}

While the two sigma-delta modulators play the key role in realizing the Hershey-Kiss modulation profile, the design of a fractional-N PLL circuit is also very important. In this section, we describe circuit components for the proposed SSCG. Extra circuit design techniques to

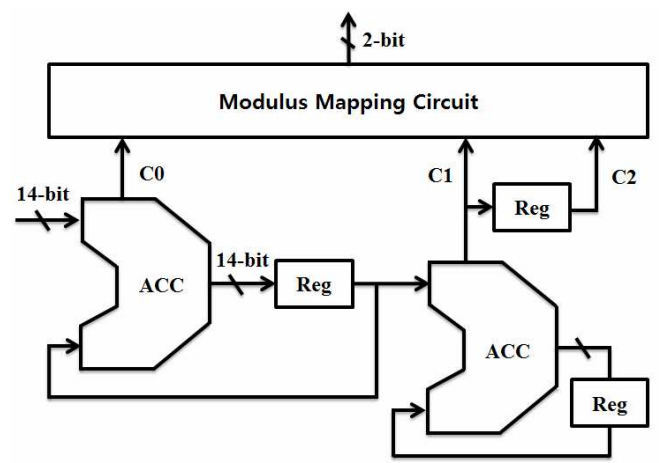

Fig. 4. Second-order MASH 1-1 sigma-delta modulator used in the division modulator.

reduce spurious tones are not applied in the fractional-N PLL design [13]. In this paper a $3^{\text {rd }}$ order loop filter was used for reducing spurious tones.

\section{Sigma-Delta Modulator}

The proposed SSCG generates the Hershey-Kiss modulation profile with sigma-delta modulators. Using sigma-delta modulators, the number of control bits can be reduced while the quantization noise is pushed into the high frequency band. There is a trade-off between the order and the stability of the SDM. In this work, the MASH (multi-stage noise shaping) type SDM can be used to keep the stability regardless of the order. Fig. 4 shows the block diagram of the $2^{\text {nd }}$ order MASH 1-1 sigma-delta modulator used in the proposed SSCG. It is formed by cascading two $1^{\text {st }}$ order sigma-delta modulators.

\section{PLL Blocks}

The PLL circuit generates 540MHz, 270MHz, and 162 $\mathrm{MHz}$ clocks for the link symbol clock signals in the DisplayPort 1.2 serial interface. Fig. 5(a) shows the schematic of the VCO which consists of a 4-stage ring oscillator. The bias voltage generator can adjust $\mathrm{V}_{N \text { BIAS }}$ dynamically by its own negative feedback loop to compensate the PVT variation. The self-biased technique can provide a wide frequency range and minimized supply /substrate noise. The delay cell of the VCO shown in Fig. 5(b) is a source-coupled pair with symmetric active loads for the better linearity of the VCO gain and wider swing [14]. 


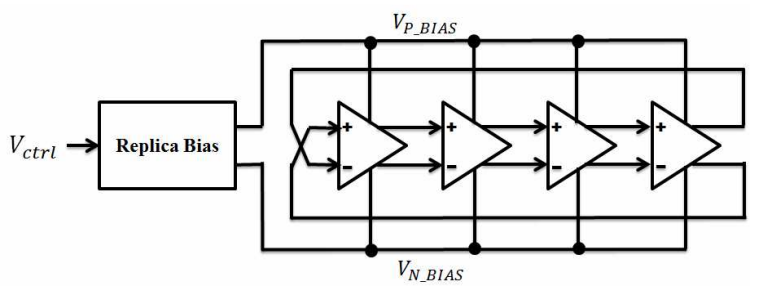

(a)

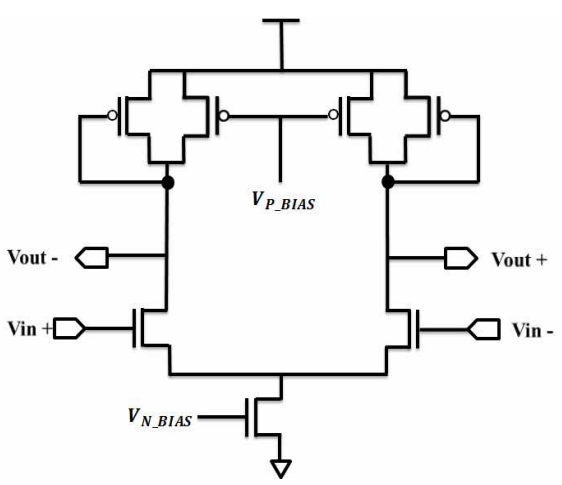

(b)

Fig. 5. Block diagram of the Voltage Controlled Oscillator (a) and its delay cell (b).

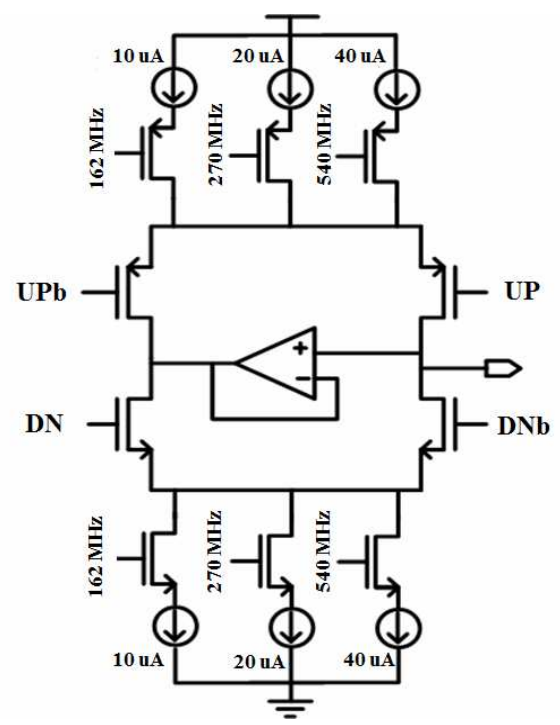

Fig. 6. Block diagram of the charge pump.

The schematic in Fig. 6 shows the charge pump circuit for the SSCG. A unity-gain buffer is used to clamp the terminal voltages of current sources during the zerocurrent pumping period. In this way, voltage glitches on the loop filter due to charge sharing can be eliminated [15]. Both the up and the down current can be either connected to the output or drained to a dummy reference voltage by the four switches. The relative timing of the charge pump switches is optimized to avoid glitches at the output node. And the proposed charge pump can switch to three current sources for $540 \mathrm{MHz}, 270 \mathrm{MHz}$, and $162 \mathrm{MHz}$ clocks. The reason we are using three different current source values is to meet the loop bandwidth because the $\mathrm{N}$ value of the MMD is difference according to the operating frequency. The loop bandwidth is set as $300 \mathrm{KHz}$ to reduce the output jitter of the circuit.

The MMD block is designed by using Verilog coding and digital synthesis. The dividing ratio of the MMD is varied with $\mathrm{N}-1, \mathrm{~N}, \mathrm{~N}+1$ and $\mathrm{N}+2 . \mathrm{N}$ value is to be decided for different clock frequencies. When the M0 signal is ' 0 ', the ' $\mathrm{N}$ ' value is set to 5 for $162 \mathrm{MHz}$ clock mode, thus the average division ratio is iterated between 5.373 and 5.4 according to output sequence of the DM. When the M0 signal is ' 1 ', the ' $N$ ' value of the MMD is set to 8 for $270 \mathrm{MHz}$ and $540 \mathrm{MHz}$ clock, and the average division ratio is iterated between 8.955 and 9 .

\section{MEASUREMENT RESULTS}

The proposed SSCG with Hershey-Kiss modulation profile for DisplayPort 1.2 has been designed using CMOS $0.13-\mu \mathrm{m}$ process. Fig. 7 shows the micrograph of the fabricated SSCG chip. Fig. 7(b) is the core layout of the proposed circuit. The area of the proposed circuit is $170 \times 500 \mu \mathrm{m}^{2}$.

Fig. 8 shows the simulated modulation profile and the original Hershey-Kiss profile at $540 \mathrm{MHz}$ clock mode with a PLL loop. It shows that the frequency of modulation profile has a frequency of $30.24 \mathrm{KHz}$. And the proposed scheme is well matched with the original Hershey-Kiss profile described in the Ref. [2]. We could not obtain the measured modulation profile since the pad for measuring the modulation profile was not drawn in

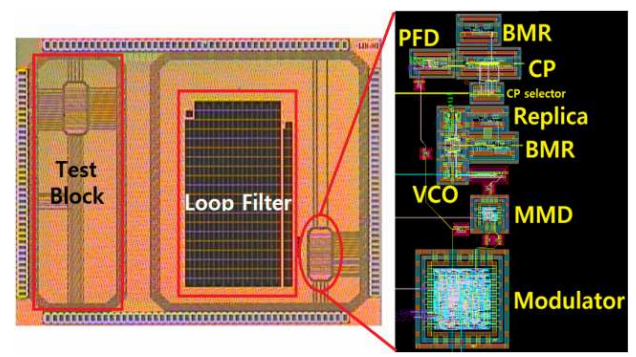

(a)

(b)

Fig. 7. (a) Chip microphoto, (b) the core blocks. 


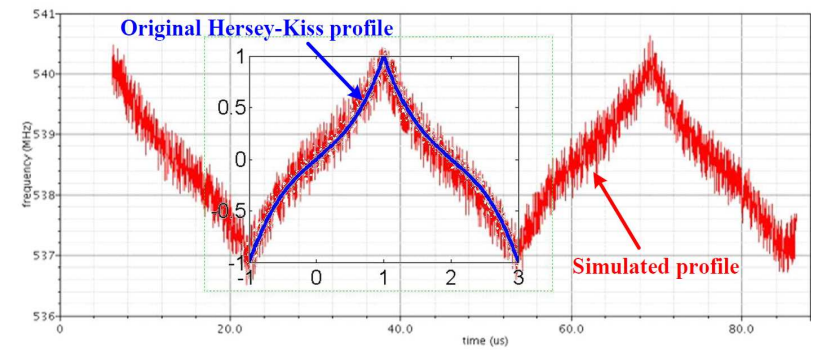

Fig. 8. Simulated modulation profile and the original HersheyKiss profile [2].

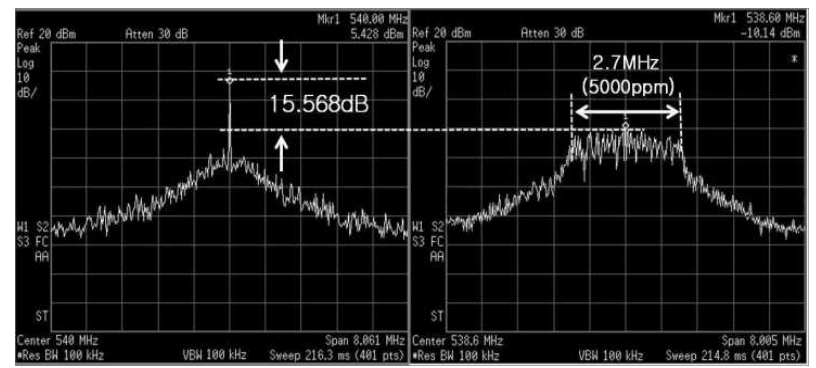

(a) $540 \mathrm{MHz}$

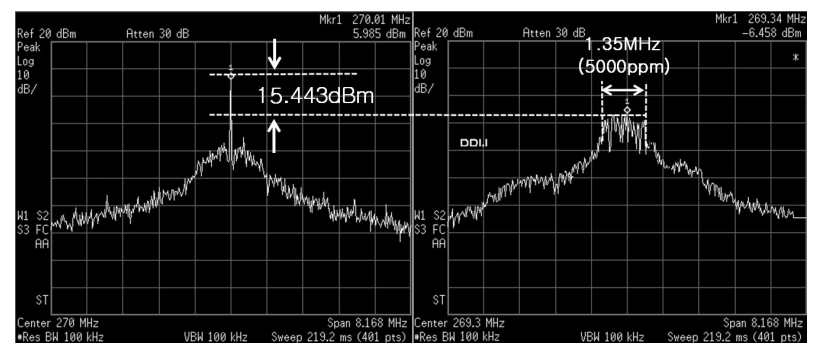

(b) $270 \mathrm{MHz}$

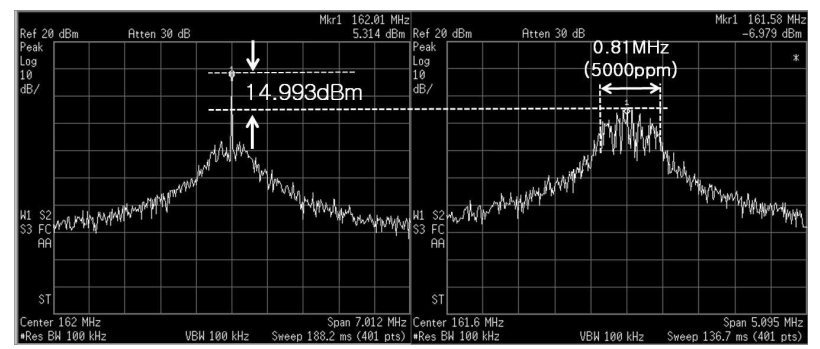

(c) $162 \mathrm{MHz}$

Fig. 9. Spectrum of SSC-off (left) and SSC-on (right) at three different rates.

the chip. However the modulation profile can be estimated indirectly from Fig. 9.

Fig. 9 shows the measured frequency spectrums at 540 $\mathrm{MHz}, 270 \mathrm{MHz}$, and $162 \mathrm{MHz}$ output clock signals, respectively. The left measured spectrums are the single tone clock in the non-SSC mode and the right sides are the spectrum of the modulated output clock with the proposed profile. Fig. 9 is showing that the power

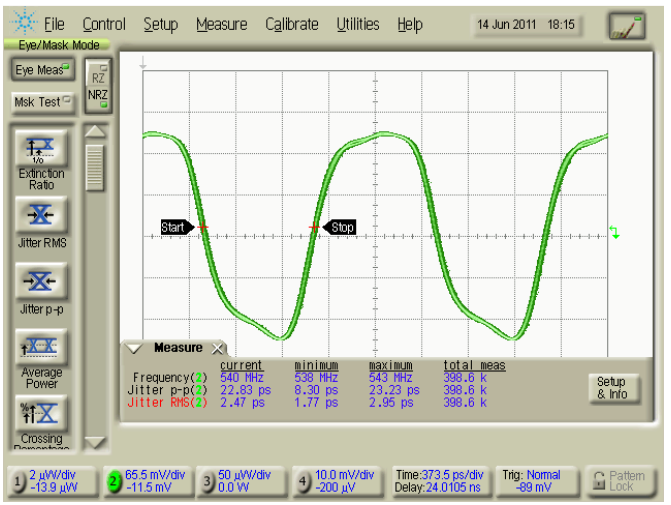

(a)

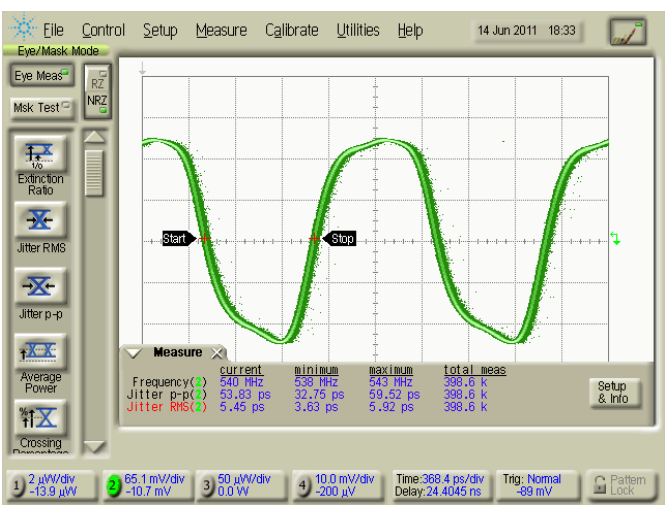

(b)

Fig. 10. Jitter Measurement of SSC-off (a) and SSC-on, (b) at $540 \mathrm{MHz}$.

reduction is about $15.6 \mathrm{~dB}$ measured with $\mathrm{RBW}$ (resolution bandwidth) of $100 \mathrm{KHz}$ comparing to the non-SSC PLL, with 5000 ppm down spread ratio for 540 $\mathrm{MHz}$ clock mode. The power reduction of $15.4 \mathrm{~dB}$ and $14.9 \mathrm{~dB}$ are achieved for $270 \mathrm{MHz}$ and $162 \mathrm{MHz}$ clock, respectively.

The jitter measurement of the circuit is shown Fig. 10. The maximum peak-to-peak jitter is 29.23 ps without SSC and 59.52 ps with SSC at $540 \mathrm{MHz}$. By using dual SDMs, the overlapped quantization noise shows up as output jitter. If the $3^{\text {rd }}$ order SDM is used instead of $2^{\text {nd }}$ SDM of division modulator, the output jitter characteristic could be improved.

Table 1 summarize the performance of the proposed SSCG. Table 2 shows the performance comparison with other designs. Our work has a lower maximum operating frequency of $540 \mathrm{MHz}$ compared to other works operating typically $1.5 \mathrm{GHz}$. To substantiate our proposed approach with utilizing a Hershey-Kiss modulation profile in SSCG design, the most peak power reduction was achieved. 
Table 1. SSCG performance summary

\begin{tabular}{|c|c|}
\hline Process technology & $0.13-\mu \mathrm{m}$ CMOS \\
\hline Supply voltage & $1.2 \mathrm{~V}$ \\
\hline Total chip area & $\begin{array}{l}1600 \times 2000 \mu \mathrm{m}^{2}(\mathrm{w} / \text { filter }) \\
170 \times 500 \mu \mathrm{m}^{2}(\mathrm{w} / \mathrm{o} \text { filter })\end{array}$ \\
\hline Modulation profile & Hershey-Kiss Profile \\
\hline Modulation frequency & $30.24 \mathrm{KHz}$ \\
\hline Spreading ratio (down) & $0.5 \%$ \\
\hline Output frequency & $540 \mathrm{MHz} / 270 \mathrm{MHz} / 162 \mathrm{MHz}$ \\
\hline VCO gain & $1.2 \mathrm{GHz} / \mathrm{V}$ \\
\hline Loop bandwidth & $300 \mathrm{KHz}$ \\
\hline Spectrum power reduction & $\begin{array}{l}15.6 \mathrm{~dB}(540 \mathrm{MHz}) \\
15.4 \mathrm{~dB}(270 \mathrm{MHz}) \\
14.9 \mathrm{~dB}(162 \mathrm{MHz})\end{array}$ \\
\hline Clock jitter (p-p) w/ SSC-on & $\begin{array}{l}59.5 \mathrm{ps}(540 \mathrm{MHz}) \\
62.4 \mathrm{ps}(270 \mathrm{MHz}) \\
63.9 \mathrm{ps}(162 \mathrm{MHz})\end{array}$ \\
\hline Clock jitter (p-p) w/ SSC-off & $\begin{array}{l}23.2 \mathrm{ps}(540 \mathrm{MHz}) \\
25.2 \mathrm{ps}(270 \mathrm{MHz}) \\
24.4 \mathrm{ps}(162 \mathrm{MHz})\end{array}$ \\
\hline $\begin{array}{l}\text { Power consumption } \\
\text { with output buffer }\end{array}$ & $\begin{array}{l}12.0 \mathrm{~mW}(540 \mathrm{MHz}) \\
11.5 \mathrm{~mW}(270 \mathrm{MHz}) \\
10.3 \mathrm{~mW}(162 \mathrm{MHz})\end{array}$ \\
\hline
\end{tabular}

Table 2. SSCG performance comparison

\begin{tabular}{|c|c|c|c|c|c|c|c|c|}
\hline & {$[3]$} & {$[4]$} & {$[6]$} & {$[16]$} & {$[17]$} & {$[18]$} & {$[19]$} & This Work \\
\hline Process & $65 \mathrm{~nm}$ & $0.18 \mu \mathrm{m}$ & $0.18 \mu \mathrm{m}$ & $0.15 \mu \mathrm{n}$ & $0.15 \mu \mathrm{m}$ & $0.18 \mu \mathrm{m}$ & $0.13 \mu \mathrm{m}$ & $0.13 \mu \mathrm{m}$ \\
\hline $\begin{array}{c}* \text { Operating } \\
\text { frequency }\end{array}$ & $1.25 \mathrm{GHz}$ & $1.5 \mathrm{GHz}$ & $1.5 \mathrm{GHz}$ & $1.5 \mathrm{GHz}$ & $1.05 \mathrm{GHz}$ & $1.5 \mathrm{GHz}$ & $3 \mathrm{GHz}$ & $0.54 \mathrm{GHz}$ \\
\hline Modulation Profile & Hershey-Kiss & $\begin{array}{c}\text { Piecewise- } \\
\text { linear }\end{array}$ & Tri-angular & Tri-angular & Tri-angular & Tri-angular & Chaotic PAM & Hershey-Kiss \\
\hline Modulation Ratio & $6 \%$ & $0.5 \%$ & $0.5 \%$ & $0.5 \%$ & $0.5 \%$ & $0.5 \%$ & $0.5 \%$ & $0.5 \%$ \\
\hline $\begin{array}{c}\text { Modulation } \\
\text { frequency }\end{array}$ & $100 \mathrm{KHz}$ & $33 \mathrm{KHz}$ & $30.1 \mathrm{KHz}$ & $31.1 \mathrm{KHz}$ & $31.6 \mathrm{KHz}$ & $33 \mathrm{KHz}$ & $33 \mathrm{KHz}$ & $30.24 \mathrm{KHz}$ \\
\hline $\begin{array}{c}\text { Peak Power } \\
\text { Reduction } \\
\text { (RBW=100 KHz) }\end{array}$ & $7.4 \mathrm{~dB}$ & $14.2 \mathrm{~dB}$ & $9.8 \mathrm{~dB}$ & $10 \mathrm{~dB}$ & $5.43 \mathrm{~dB}$ & $14.77 \mathrm{~dB}$ & $14 \mathrm{~dB}$ & $15.6 \mathrm{~dB}$ \\
\hline $\begin{array}{c}\text { Jitter (rms) } \\
\text { RBW } 1 \mathrm{MHz})\end{array}$ & $\mathrm{NA}$ & $* * 3.77 \mathrm{ps}$ & $3.2 \mathrm{ps}$ & $8.1 \mathrm{ps}$ & $\mathrm{NA}$ & 5.55 & $5.4 \mathrm{ps}$ & $5.92 \mathrm{ps}$ \\
\hline Jitter (peak-peak) & $* * 93 \mathrm{ps}$ & $* * 27.88 \mathrm{ps}$ & $58.3 \mathrm{ps}$ & $\mathrm{NA}$ & $\mathrm{NA}$ & $34.2 \mathrm{ps}$ & $\mathrm{NA}$ & $59.6 \mathrm{ps}$ \\
\hline $\begin{array}{c}\text { Power } \\
\text { Consumption }\end{array}$ & $44 \mathrm{~mW}$ & $40 \mathrm{~mW}^{2}$ & $\mathrm{NA}$ & $54 \mathrm{~mW}$ & $\mathrm{NA}$ & $34.2 \mathrm{~mW}$ & $14.7 \mathrm{~mW}$ & $12 \mathrm{~mW}$ \\
\hline \begin{tabular}{c} 
Chip-Area \\
\hline
\end{tabular} & $0.044 \mathrm{~mm}{ }^{2}$ & $0.49 \mathrm{~mm}^{2}$ & $1.645 \mathrm{~mm}^{2}$ & $0.42 \mathrm{~mm}^{2}$ & $5.72 \mathrm{~mm}^{2}$ & $0.17 \mathrm{~mm}{ }^{2}$ & $0.21 \mathrm{~mm}{ }^{2}$ & $0.085 \mathrm{~mm}^{2}$ \\
\hline
\end{tabular}

*Measured frequency $\quad * *$ Measured with SSC-off

\section{Conclusions}

An SSCG circuit generating a Hershey-Kiss modulation profile using two sigma-delta modulators is designed for the DisplayPort 1.2 standard. Since the modulator is implemented by digital blocks, it can be modified upon different applications and spectrum spreading parameters. The circuit is implemented using $0.13 \mu \mathrm{m}$ CMOS technology and the measured results show that the maximum peak power reduction of $15.6 \mathrm{~dB}$ at $540 \mathrm{MHz}$ with $5000 \mathrm{ppm}$ down spreading for the DisplayPort 1.2 standard. 


\section{ACKNOWLEDGEMENT}

This work was supported by the NRF (No. 2013 R1A2A2A01015738), the ITRC program supervised by NIPA (NIPA-2013-H0301-13-1010, 1013). Authors also thank the IDEC program and for its hardware and software assistance for the design and simulation.

\section{REFERENCES}

[1] K. B. Hardin, J. T. Fessler, and D. R. Bush, "Spread Spectrum Clock Generation for the Reduction of Radiated Emissions," in Proc. IEEE International Symposium on Electromagnetic Compatibility, pp.227-231, Aug., 1994.

[2] K. Hardin, R. A. Oglesbee, and F. Fisher, "Investigation Into the Interference Potential of Spread-Spectrum Clock Generation to Broadband Digital Communications," IEEE Transactions on Electromagnetic Compatibility, Vol.45, No.1, pp.10-21, Feb., 2003.

[3] D. D. Caro, C. A Romani, A. G. Maria, and C. Parrella, "A 1.27GHz, All-Digital Spread Spectrum Clock Generator/Synthesizer in $65 \mathrm{~nm}$ CMOS," IEEE J. Solid-State Circuits, Vol.45, No.5, pp.1048-1060, May 2010.

[4] M. Song, S. Ahn, I. Jung, Y. Kim, and C. Kim, "1.5 $\mathrm{GHz}$ Spread Spectrum Clock Generator with a 5000ppm Piecewise Linear Modulation," in Proc. IEEE CICC, pp. 455-458, Sep., 2008.

[5] S. Hwang, M. Song, Y. Kwak, I. Jung and C. Kim, "A $0.076 \mathrm{~mm}^{2} \quad 3.5 \mathrm{GHz}$ Spread-Spectrum Clock Generator with Memoryless Newton-Raphson Modulation Profile in $0.13 \mu \mathrm{m}$ CMOS" in Proc. IEEE ISSCC Dig. of Tech papers, Feb., 2011.

[6] H. R. Lee, O. Kim, G. Ahn, and D. K. Jeong, "A low-jitter 5000ppm spread spectrum clock generator for multi-channel SATA transceiver in $0.18 \mu \mathrm{m}$ CMOS," in Proc. IEEE ISSCC Dig. of Tech Papers, pp.162-163, Feb., 2005.

[7] W. T. Chen, J. C. Hsu, H. W. Lune and C. C. Su, "A Spread Spectrum Clock Generator for SATAII," IEEE International Symposium on Circuits and Systems, pp.2643-2646, May 2005.

[8] M. Kokubo, T. Kawamoto, T. Oshima, T. Noto, M. Suzuki, S. Suzuki, T. Hayasaka, T. Takahashi and J. Kasai, "Spread-Spectrum Clock Generator for
Serial ATA using Fractional PLL Controlled by $\Delta \Sigma$ Modulator with Level Shifter," in Proc. IEEE ISSCC Dig. of Tech Papers, pp.160-161, Feb., 2005.

[9] D. S. Kim and D. K. Jeong, "A Spread Spectrum Clock Generation PLL with Dual-tone Modulation Profile" Symposium on VLSI Circuits Dig. of Tech Papers, pp.96-99, June 2005.

[10] J. W. Lee, H. J. Kim, C. Yoo, "Spread Spectrum Clock Generation for Reduced Electro-Magnetic Interference in Consumer Electronics Devices", IEEE Transactions on Consumer Electronics, Vol. 56, No.2, pp.844-847, May 2010.

[11] H. Park and J. Kang, "SSCG with Hershey-Kiss modulation profile using Dual Sigma-Delta modulators", IEICE Express, Vol.7, No.18, pp.1349-1353, Sep., 2010.

[12] VESA, VESA DisplayPort Standard, version 1, Revision 2, Jan. 2010.

[13] K. J. Wang, A. Swaminathan, and I. Galton, "Spurious Tone Suppression Techniques Applied to a Wide-Bandwidth $2.4 \mathrm{GHz}$ Fractional-N PLL," IEEE J. Solid-State Circuits, Vol.43, No.12, pp.2787-2797, Dec., 2008.

[14] J. G. Maneatis, "Low-Jitter Process-Independent DLL and PLL Based on Self-Biased Techniques," IEEE J. Solid-State Circuits, Vol.31, No.11, pp.1723-1732, Nov., 1996.

[15] I. A. Young, "A PLL Clock Generator With 5 to $110 \mathrm{MHz}$ of Lock Range for Microprocessors", IEEE J. Solid-State Circuits, Vol. 27, No. 11, pp. 1599-1607, Nov., 1992.

[16] M. Kokubo, T. Kawamoto, T. Oshima, T. Noto, M. Suzuki, S. Suzuki, T. Hayasaka, T. Takahashi, and J. Kasai, "Spread-Spectrum Clock Generator for Serial ATA with Multi-Bit Sigma-Delta Modulator-Controlled Fractional PLL," IEICE Trans. Electron., Vol. E89-C, No.11, pp.16821688, Nov., 2006.

[17] M. Aoyama et al., "3 Gbps, 5000 ppm Spread Spectrum SerDes PHY with Frequency Tracking Phase Interpolator for Serial ATA," Symposium on VLSI Circuits Dig. of Tech Papers, pp.107-110, June 2003.

[18] D. S. Shen, and S. I. Liu, "A Low-Jitter Spread Spectrum Clock Generator using FDMP," IEEE Trans. Circuits and Systems II, Vol.54, No.11, 
pp.979-983, Nov., 2007.

[19] F. Pareschi, G. Setti, and R. Rovatti, “A 3-GHz Serial ATA Spread-Spectrum Clock Generator Employing a Chaotic PAM Modulation," IEEE Trans. Circuits and Systems I, Vol.57, No.10, pp.2577-2587, Oct., 2010.

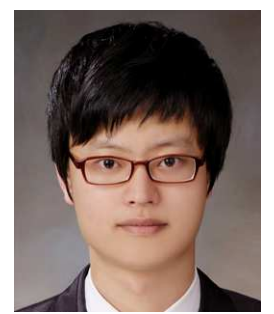

Seung-Wook Oh received the BS degree in electronics engineering from Inha University, Incheon, Ref. of Korea, in 2011 and is currently working toward the M.S. degree in electronic engineering. His research interests include high-speed interface IC, PLL, SSCG and analog/digital mixed circuit design.

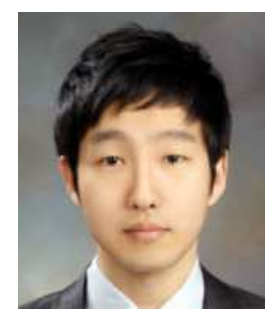

Hyung-Min Park received the BS and MS in electronics engineering from Inha University, Incheon, Rep. of Korea, in 2009 and 2011, respectively. Since 2011, he has been with Hyundai Autron Co., Seongnam, Ref. of Korea. His research interests include high-speed clock generation and VLSI circuit design.

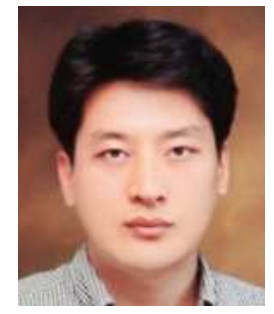

Yong-Hwan Moon received the BS and MS in electrical engineering in 2002 and 2004, respectively, from Inha University, Incheon, Rep. of Korea. $\mathrm{He}$ is currently working toward the $\mathrm{PhD}$ in the Department of Electrical and Engineering, Inha University. His research interests include high-speed interface and clock and data recovery circuits.

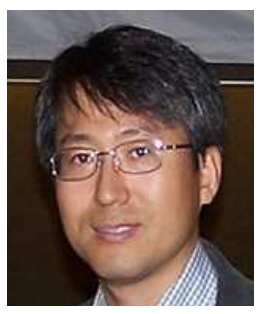

Jin-Ku Kang received his $\mathrm{PhD}$ in electrical engineering from North Carolina State University in 1996. From 1983 to 1988, he worked at Samsung Electronics, Inc., Korea. From 1996 to 1997, he was with Intel as a senior design engineer. Since 1997, he has been a professor in the School of Electronics Engineering, Inha University, Rep. of Korea. His research interests are high-speed CMOS VLSI design, mixed-mode IC design, and high speed serial interface design. 